\title{
Avaliação da aprendizagem em contextos de inclusão escolar
}

Márcia Marin*

Patricia Braun**

\section{Resumo}

A avaliação escolar é uma atividade docente que demanda observação sistemática e processual sobre a aprendizagem e desenvolvimento dos estudantes de modo geral. Contudo, o modo como foi constituída gerou modelos de classificação que privilegiam a homogeneidade sobre o processo escolar. E quando há um estudante que apresenta uma especificidade em seu desenvolvimento o contexto da avaliação gera problematizaçôes. Assim, este texto tem por finalidade abordar a questão da avaliação da aprendizagem num contexto de inclusão escolar, refletir sobre as crenças teóricas e práticas para estudantes com deficiência intelectual ou autismo que exigem respostas educativas ajustadas às suas necessidades e apresentar algumas práticas desenvolvidas. Para esta pauta, a base metodológica se fez a partir da revisão da literatura científica sobre o tema, em diálogo com relatos de experiências envolvendo práticas de avaliação desenvolvidas em duas escolas públicas de educação básica, do município do Rio de Janeiro. A revisão da literatura indica que os estudos sobre o tema, embora denso e urgente, ainda são poucos, principalmente em relação a práticas cotidianas e sistemáticas que compóem um ano letivo. As experiências sobre o cenário das duas escolas alvo deste trabalho revelam que, além da mediação ser confirmada como fator essencial nesse processo, as práticas de avaliação para os estudantes apresentam sentido e favorecem o desenvolvimento quando há a organização de instrumentos e estruturas escolares (tempo, espaço, recursos humanos e materiais) minimamente pensados e disponibilizados conforme se observam as demandas e especificidades sobre esse aprender.

Palavras-chave: Avaliaçáo da aprendizagem; Prática pedagógica; Deficiência intelectual; Autismo.

\footnotetext{
* Professora doutora do Colégio Pedro II, Rio de Janeiro, Rio de Janeiro, Brasil.

** Professora doutora do Instituto de Aplicaçáo Fernando Rodrigues da Silveira CAp-UERJ, Rio de Janeiro, Rio de Janeiro, Brasil.
} 


\section{Assessment of learning in contexts of school inclusion}

\section{Abstract}

School evaluation is a teaching activity that demands systematic and procedural observation about student learning and development in general. However, the way it was constituted generated classification models that favor homogeneity over the school process. And when there is a student that presents a specificity in its development the context of the evaluation generates problematizations. Thus, this text aims to address the issue of learning assessment in a context of school inclusion, reflect on the theoretical and practical beliefs for students with intellectual disabilities or autism that require educational responses tailored to their needs and present some developed practices. For this agenda, the methodological basis was based on the review of the scientific literature on the subject, in dialogue with reports of experiences involving evaluation practices developed in two public schools of basic education, in the city of Rio de Janeiro. The review of the literature indicates that studies on the subject, although dense and urgent, are still few, mainly in relation to the daily and systematic practices that make up a school year. The experiences of the two schools in this study show that, in addition to mediation being confirmed as an essential factor in this process, the evaluation practices for students make sense and promote development when there is the organization of school instruments and structures (time, space, human and material resources) minimally thought out and made available as the demands and specificities on this learning are observed.

Keywords: Learning assessment; Pedagogical practice; Intellectual disability; Autism.

\section{Evaluación del aprendizaje en contextos de inclusión escolar}

\section{Resumen}

La evaluación escolar es una actividad docente que exige observación sistemática y procesal sobre el aprendizaje y el desarrollo de los estudiantes en general. Sin embargo, el modo como fue constituido generó modelos de clasificación que privilegia la homogeneidad sobre el proceso escolar. Y cuando hay un estudiante que presenta una especificidad en su desarrollo, el contexto de la evaluación genera problemas. Así, este texto tiene por finalidad abordar la cuestión de la evaluación del aprendizaje en un contexto de inclusión escolar, reflexionar sobre las creencias teóricas y prácticas para estudiantes con discapacidad intelectual o autismo que exigen respuestas educativas ajustadas a sus necesidades y presentar algunas prácticas desarrolladas. Para esta pauta, la base metodológica se hizo a partir de la revisión de la literatura científica sobre el tema, en diálogo con relatos de experiencias involucrando prácticas de evaluación 
desarrolladas en dos escuelas públicas de educación básica, del municipio de Río de Janeiro. La revisión de la literatura indica que los estudios sobre el tema, aunque denso y urgente, todavía son pocos, principalmente en relación a prácticas cotidianas y sistemáticas que componen un año lectivo. Las experiencias sobre el escenario de las dos escuelas objetivo de este trabajo revelan que, además de la mediación ser confirmada como factor esencial en este proceso, las prácticas de evaluación para los estudiantes presentan sentido y favorecen el desarrollo cuando hay la organización de instrumentos y estructuras escolares (tiempo, espacio, recursos humanos y materiales) minimamente pensados y disponibles conforme se observan las demandas y especificidades sobre ese aprendizaje.

Palabras-clave: Evaluación del aprendizaje; Práctica pedagógica; Discapacidad intelectual; Autismo.

É sobre o cotidiano de uma escola comum que quero refletir neste trabalho, tomando com especial atenção a avaliação, prática tradicionalmente imersa na previsibilidade, na repetição e no saber, mas que também guarda em si o oposto (ESTEBAN, 2002, p. 131).

O desafio de escrever um texto que aborde a questão da avaliação da aprendizagem num contexto de inclusão escolar provoca reflexão e revisão de nossas posiçóes teóricas e práticas, pois o contexto é de estudantes com especificidades no seu desenvolvimento, que exigem respostas educativas ajustadas tanto às suas necessidades quanto à realidade escolar cotidiana (adversa) em que vivemos.

Como professoras da educação básica e pesquisadoras da área de Educação Especial estamos, muitas vezes, no "olho do furacão" e temos que tomar decisôes, minimamente, coerentes com o que teorizamos. São conflitos, desafios e decisões do e no dia a dia.

Nossa intenção é que este material escrito não seja "mais do mesmo", vamos tentar... O objetivo é trazer problematizaçôes sobre práticas de avaliação.

Deste modo, iniciamos contextualizando e levantando questóes que nos movem; na sequência, há um levantamento de literatura que trata de avaliação da aprendizagem, trazemos produçôes sobre o tema de modo geral e com relação à Educação Especial e inclusão; por fim, seguem experiências construídas na prática cotidiana das salas comuns, de escolas públicas onde somos professoras.

Para melhor compreensão: por que em tempos de inclusão falamos de Educação Especial? Assumimos a concepção de que Educação Especial se constitui numa área de conhecimento específica, que pode contribuir para o desenvolvimento de práticas pedagógicas colaborativas, envolvendo docentes com conhecimentos distintos e complementares.

Essa é uma perspectiva situada num determinado contexto, pois à medida em que vivenciamos processos de inclusão numa escola que tem ainda muitos mecanismos excludentes, precisamos, por um tempo, de profissionais de referência que 
promovam o diálogo e provoquem outras práticas em torno de estudantes que exigem propostas diferenciadas. Prospectivamente, ansiamos por uma escola onde todos dialoguem sobre as diferenças e a diversidade, sem tantas classificaçôes e sem a necessidade de "especialistas".

"Cada um interpreta inclusão a seu modo. Não é possível abarcar numa única frase conceitos táo complexos como este" (BOOTH; AINSCOW, 2011, p. 20). Assim, temos outro ponto a esclarecer, para inserir o tema de práticas de avaliação, é o conceito de inclusão que perseguimos, que consiste na garantia do tripé do acesso-permanência-aprendizagem de pessoas com deficiência, autismo e outras especificidades (AINSCOW, 2001), conforme orienta a Política Nacional, declarando que os sistemas de ensino devem se organizar para garantir: "acesso ao ensino regular, com participação, aprendizagem e continuidade nos níveis mais elevados do ensino" (BRASIL, 2008).

Deste modo, avaliaçấo da aprendizagem é uma ação inerente ao ato educativo e sempre assunto complexo e ponto de pauta do trabalho docente. Algumas questóes persistem - como avaliar? O que avaliar? Para quê avaliar? Como saber se cada estudante aprendeu o que foi ensinado? A avalição é essa possibilidade de compreensão do que se aprende e de como se ensina para promover a aprendizagem.

Cabe, ainda, situar os leitores de que os contextos institucionais em que atuamos não fogem dos modelos tradicionalmente conhecidos em relação às práticas de avaliação: escolas com notas de 0 a 10; média 7,0; momentos ritualísticos de provas; instrumentos de avaliaçáo comum a todos, com recortes de conteúdos que precisam ser demonstrados por meio de uma linguagem única, privilegiadamente a escrita; os produtos finais - trabalhos, testes, provas - são a principal fonte para a pontuação e classificação; quem não consegue as médias faz o ano escolar novamente, numa organização seriada.

Sem sermos simplistas ou cairmos em repetiçóes e chavôes, temos por objetivo abordar práticas avaliativas que envolvem estudantes com deficiência intelectual e estudantes com autismo, que é o alunado com o qual lidamos mais e que apresentam, na nossa experiência particular, desafios bem específicos.

Primeiramente, é preciso esclarecer que adotamos avaliação numa perspectiva emancipatória, como processo, formativa, com caráter de revisar procedimentos de ensino para promover aprendizagem e desenvolvimento.

Nesse contexto adverso e contraditório buscamos responder algumas perguntas: o estudante aprendeu o que foi ensinado? O que ele sabe? O que precisamos ensinar?

Vejamos um pouco do que a produçáo acadêmica nos traz como aporte teórico para pensarmos nessas questóes.

\section{Avaliação e escolarização: ideias iniciais}

Como avaliar crianças que todo o tempo fogem dos padróes pré-estabelecidos e para as quais parece que nenhum parâmetro é suficiente? (ESTEBAN, 2002, p.133). 
Todos os alunos aprendem? Como construir diferentes estratégias de intervenção pedagógica para um mesmo grupo? Como avaliar considerando as singularidades dos alunos? (BAPTISTA e CHRISTOFARI, 2012, p. 383).

A distância de tempo entre os questionamentos de Esteban (2002) e de Baptista e Christofari (2012) soma uma década. Todavia, é notável observar que a escola e as questôes sobre avaliação escolar, de um tempo e de outro, têm a mesma base, assim como a escola tem permanecido com a mesma estrutura.

Em ambos os trabalhos, mesmo sendo o primeiro no campo da educação comum e o segundo no campo da educação especial, há a mesma problematização que envolve a avaliação: como fazer quando a singularidade para aprender e ensinar se impóe ao que está estabelecido?

$\mathrm{Na}$ verdade, o ingresso de estudantes com deficiência ou autismo na escola comum só ampliou questionamentos com os quais ela já lidava, em função de sua estrutura pouco flexível, que se mantém e origina dos primórdios da organização da escola, como afirmam Carminati e Borges (2012, p. 162), com base em Foucault,

[...] após 1762, a escola inicia sua organização, seja do espaço dos indivíduos, da arquitetura escolar, das disciplinas enquanto conteúdo; dos exames como prova de comprovação ou medição do saber alcançado; buscando sempre uma classe homogênea e marcando uma hierarquia do saber e da capacidade. É a partir desse momento histórico que se sequestram crianças, prendem-nas em prédios, impóem horários, disciplina, toda uma maquinaria escolar, onde se institui ainda o prêmio; sempre vinculado ao processo de avaliação (grifo nosso).

Deste modo, as propostas escolares que preveem a homogeneidade acabam por deflagrar equívocos sobre o fazer pedagógico. E a escola, como um importante lugar de acesso aos bens culturais elaborados pela sociedade, passa a lidar com o fracasso, a retenção e a evasão.

Em relação à avaliação da aprendizagem, cria-se um cenário onde ela é entendida como o que há de mais importante na escola por muitos, sejam professores, estudantes ou familiares. É como se a avaliaçáo fosse um fim e não parte do processo. O olhar sobre o processo, nesse sentido, fica frágil, além de não "avançar nas grandes finalidades da escola - aprendizagem efetiva, desenvolvimento humano pleno e alegria crítica [...]" para cada um dos seus estudantes, assim dizem Pacheco e Pacheco (2012, p. 14). A compreensão de avaliação como parte do processo escolar, apresenta a necessidade de conhecer o estudante e, sobretudo, reconhecê-lo como sujeito com direito de aprender.

Nesse contexto, o docente desempenha o papel de mediador a cada atividade desenvolvida e, na medida em que observa como o estudante se envolve no processo, aprende sobre como este elabora seu pensamento, realiza suas atividades e constrói seu conhecimento. A partir dessa clareza sobre o processo didático-pedagógico que se estabelece, há a possibilidade de elaborar intervençóes, planejar intencionalmente para promover o desenvolvimento das estruturas de pensamento do jovem estudante. 
O tempo de observar, analisar e propor situaçōes de ensino para novas aprendizagens se configura como o momento mais propício e qualificado de avaliação (HOFFMANN, 2002).

Corroboram com este pensamento Pacheco e Pacheco (2012, p. 14-15) que enfatizam a relevância da avaliaçáo como estratégia, uma vez que:

$$
\begin{aligned}
& \text { uma boa avaliação aponta os elementos potenciais, qual seja, que } \\
& \text { não estão ligados aos objetivos inicialmente traçados - ficando, } \\
& \text { portanto, fora da questáo do acerto ou do erro [...]. }
\end{aligned}
$$

Tal pensamento se alinha aos estudos de Vigostski (2000, 2008). A ação pedagógica com base na zona de desenvolvimento iminente (PRESTES, 2012) se traduz, no nosso entender, como tempo e espaço onde a avaliaçáo melhor se configura como estratégia para validação tanto do ensino quanto da aprendizagem. Ou seja, a análise sobre o que se estabelece como aprendizagem, a partir do que foi ofertado como ensino, se apresenta extremamente reduzida se considerada somente a partir da análise de produtos finais como uma prova, por exemplo.

Entáo, o que pode ser percebido como erro é, de fato, o que não foi aprendido pelo estudante ou é o que está em processo de aprendizagem? O ponto que nos parece ser contundente, ao considerarmos a avaliação da aprendizagem, é estabelecer como desenvolver as funçóes superiores que constituem o desenvolvimento cultural e do pensamento do estudante - "a linguagem, a escrita, o cálculo, o desenho; [...] a memória, a lógica, a formação de conceitos" (VIGOSTSKI, 2000, p. 29).

As análises e questionamentos sobre como a avaliação na escola pode ser compreendida e realizada, com vistas à aprendizagem, abordaram até aqui aspectos gerais. Isso com a intenção de referendar a concepção de onde partimos, mas principalmente para desmistificar a relação entre a presença do estudante com deficiência ou autismo e as problematizaçôes comuns a todos referentes a essa temática.

Reconhecemos que o desenvolvimento peculiar de alguns estudantes suscita análises e açôes específicas. Entretanto, muitas questóes referentes à avaliação já estavam lá. Nas palavras de Oliveira (2018, p. 63), “o ideário de inclusáo escolar recoloca a problemática de uma organizaçáo homogênea, padronizada e linear que tem sustentado a escola, seja na sua estrutura, seja na sua relação pedagógica”.

\section{Avaliação da aprendizagem com estudantes com deficiência intelectual ou com autismo}

Christofari e Baptista (2012, p. 385) entendem a avaliação da aprendizagem,

[...] como um processo que deve envolver o grupo-classe, sem diferenciaçóes na lógica avaliativa, ainda que se possa recorrer a procedimentos que indicam certa variabilidade. De acordo com essa perspectiva, os alunos com deficiência devem ser avaliados de maneira semelhante a seus colegas, e aquilo que deve se diferenciar, com maior evidência, são as estratégias de ensino, os materiais e apoio utilizados no cotidiano escolar. 
Em se tratando de estudantes com deficiência intelectual ou autismo, acordamos com a referida abordagem, na medida em que o "grupo-classe" é referência para as aproximaçóes curriculares avaliativas, de modo a não isolar o estudante do processo e de seus pares.

É importante refletir sobre esta aproximação, pois o que se aponta é um fazer diferente e ajustado ao currículo proposto. As finalidades da avaliação para a aprendizagem seriam, entáo, favorecer novas aprendizagens com base na proposta curricular ampla e indicar as diferenciaçóes necessárias para promover a aprendizagem, no lugar de focar nas dificuldades ou restrições (OLIVEIRA, 2018).

Guardada a devida atenção sobre a organização da flexibilizaçáo destes componentes curriculares, de modo que a proposição propicie ao estudante estar e participar do coletivo dos pares de sua turma, a avaliação da aprendizagem em suas estratégias exigirá, invariavelmente, que "se pense não em avaliar o que ele já sabe ou não sabe, mas em como acrescentar conhecimentos àquilo que ele já aprendeu. E, nessa direção, a ideia de semelhança sobre este processo se estabelece quando a escola "percebe as diferenças presentes na sala de aula e muda suas práticas com todos os alunos" (VIEIRA e MONTEIRO, 2014, p. 100).

Assim, as estratégias de avaliação para a aprendizagem tornam-se válidas quando permitem a observação sobre "as necessidades específicas e particulares destes escolares com deficiência intelectual e quais os apoios necessários para que possa se garantir a sua aprendizagem" (OLIVEIRA, 2018, p. 82). Com autismo, da mesma forma.

As análises realizadas até aqui levam a considerar que a avaliação da aprendizagem é, em primeira instância, um mapeamento que envolve o ensino, a aprendizagem e os apoios necessários para estudantes e docentes.

A reflexão sobre este debate é densa, mas ainda pouco sistematizada ou disseminada. Estudos que envolvem estudantes com deficiência intelectual têm prevalência sobre os estudos com estudantes com autismo, neste cenário. Alguns dos poucos estudos que encontramos sobre a temática abordam, em linhas gerais, a avaliação como diagnose para a aprendizagem (OLIVEIRA e CAMPOS, 2005; CAPELLINI e MENDES, 2008; CARNEIRO, 2012; SILVA e MELETI, 2012; JESUS e AGUIAR, 2012; CORREIA e TONINI, 2012; CARDOSO e MAGALHÃES, 2012; OLIVEIRA, VELENTIN e SILVA, 2013; OLIVEIRA e CAMPOS, 2015; OLIVEIRA, PLESTCH e OLIVEIRA, 2016, OLIVEIRA 2018).Também consideramos alguns documentos nacionais, que seguem a mesma linha (BRASIL, 2005; SÃO PAULO, 2012).

Isso quer dizer que os trabalhos encontrados trazem dados e reflexôes sobre as estruturas já estabelecidas por estudantes, para um determinado conhecimento escolar, geralmente com apontamentos sobre a escrita, leitura ou matemática dos anos iniciais da educação básica ou percepções de professores sobre o processo de avaliação. Trata-se assim de abordagens que revelam aspectos sobre uma avaliaçáo específica, a qual, como definem Oliveira e Campos (2005, p. 74.), "busca estabelecer a capacidade de desenvolvimento do aluno, mediante a identificaçáo de suas necessidades individuais e específicas". 
Para além desse tipo de avaliação, sem dúvida essencial para a projeção de todo o trabalho pedagógico curricular, a "avaliação compreensiva ou de acompanhamento", como denominam as referidas autoras, é, ao nosso ver, o ponto de maior questáo, por ser a que trata do olhar sobre o cotidiano do que é abordado em sala de aula, dia a dia, a cada período e que, em um determinado momento do ano letivo, a escola prevê atividades para a verificação. Esta

[...]busca a análise do desempenho escolar e curricular do aluno,
por meio de um instrumento de avaliaçáa (elaborado pelo próprio
professor) para conhecer as condiçôs de aprendizagem dos alunos,
a sua competência curricular e estabelecer estratégias de ensino,
recursos e procedimentos de apoio para subsidiar o planejamento
pedagógico (OLIVEIRA e CAMPOS, 2005, p. 74-75).

Ou seja, o debate sobre como tem ocorrido este acompanhamento sistemático, sobre os instrumentos, seus formatos e formas de aplicação, que dizem respeito às estratégias metodológicas adotadas para a avaliação da aprendizagem é o que suscita questôes e problematizaçóes dado o sistema "regular", meritocrático, com tempos e modos fechados para demonstrar este aprender.

Ao considerarmos a avaliação da aprendizagem em relação a estudantes com deficiência intelectual e autismo na escola comum, confirmamos que ela, como afirmam Capellini e Mendes (2008, p. 9), precisa ser "caracterizada por agir essencialmente, como instrumento regulador dos processos de ensino e de aprendizagem, ampliando e superando claramente os níveis de rendimento alcançados pelos alunos, somente como notas".

A mediação é, neste sentido, uma das estratégias fundamentais neste contexto. Oliveira e Campos $(2015$, p. 4) ratificam a relevância disto ao afirmarem que é importante garantir a ajuda necessária [leia-se, apoio por via da mediaçáo docente] ao aluno lhe dando maiores condiçóes para a resolução das tarefas, além de, na prática, desmistificar "o pensamento de que o suporte pedagógico náo deve ocorrer durante a fase da avaliaçẫo".

$\mathrm{Na}$ cultura escolar em que estamos imersos, a mediação em momentos de avaliaçóes ainda é um fator a ser qualificado. É comum o entendimento de que válida é a resposta que o estudante faz sozinho. No caso de muitos, esta concepção em nada favorece a análise sobre a aprendizagem do estudante. Em se tratando daqueles com deficiência intelectual ou autismo isso é ainda mais certo, pois para estes a mediação estabelecida por um docente, ou seja, a mediçáo externa, é condição para a estruturaçáo de muitos dos processos de pensamento requeridos para a elaboração da atividade (PITANGA DE OLIVEIRA, PLETSCH e OLIVEIRA, 2016).

Carneiro (2012, p. 525) apresenta um aspecto que nos é muito caro, neste sentido. Diz que "a avaliação da aprendizagem será sempre tarefa do professor regente, daquele que planejou o processo de ensino/aprendizagem. Tal tarefa pode ser compartilhada com outro profissional [...]". Sobre isto entendemos que não é uma escolha, mas uma necessidade compartilhar a tarefa de elaborar e aplicar o instrumento de avaliação porque, nem só os professores da área curricular específica e nem só 
os professores especialistas em educação especial conseguem, isoladamente, agir sobre esta dinâmica. Os conhecimentos curriculares e os didático-pedagógicos de ambos docentes podem compor, de forma mais adequada, a elaboração de instrumentos e procedimentos metodológicos que melhor atendam a especificidade do estudante em questão.

Notamos que práticas avaliativas isoladas, como as muitas que ocorrem exclusivamente no âmbito do espaço das salas de recursos, podem ficar mascaradas como não válidas ou de menor valor, ou ainda como confirmação dos limites e "incapacidades". Jesus e Aguiar (2012, p.399) revelam que "os procedimentos avaliativos iniciais estáo fortemente remetidos à ideia de laudos de profissionais da área clínica, cabendo ao professor especialista, junto com o professor de sala regular, somente a identificação inicial de condiçôes da não aprendizagem".

Também se configura como outra fragilidade séria o retrato da participação destes estudantes em aplicaçóes de avaliaçôes de larga escala, as quais deveriam prever análises para a melhoria do processo para a aprendizagem dos mesmos. Todavia, como apontam Silva e Meletti, (2012, p.417), primeiro, a "participação dos alunos com necessidades educacionais especiais nas avaliaçôes em larga escala é mínima, o que denota a ideia de ambiguidade entre discurso e prática inclusiva”. E, segundo, este tipo de instrumento não se configura como "um modelo avaliativo capaz de representar a real aprendizagem do aluno" (p.429), por diversos fatores sobre os quais não nos deteremos, mas se fazem presentes e não são considerados em relação ao momento, às condiçôes desse aluno e do ambiente escolar. É um sistema que coloca em xeque as dinâmicas da avaliação para a aprendizagem e revela "a existência do subterfúgio que cria as 'crianças da margem', mostra os requintes dos processos excludentes recorrentes nos sistemas escolares", como afirmam Cardoso e Magalhães (2012, p. 462).

\section{Práticas de avaliação constituídas na e pela necessidade de fazer diferente e de modo equânime}

Atuando na educaçáo básica, buscando a garantia de promover a aprendizagem de estudantes em processos de inclusão, trazemos aqui algumas práticas avaliativas que foram construídas a partir de desafios que se apresentaram no dia a dia da vida escolar. Vamos apontar práticas de avaliação mediada, que se desdobram em várias estratégias diferenciadas, tais como: avaliaçôes orais, com escriba, com ledor, com apoio de objetos pedagógicos. Além disso, vamos indicar alguns instrumentos de registro que foram necessários para compor o processo de avalição.

Avaliação mediada foi o principal procedimento a ser adotado junto a estudantes com deficiência intelectual ou autismo. Nos momentos de avaliação formal, o acompanhamento de um docente durante a realizaçáo da prova (que todo mundo faz "sozinho") passou a ser uma ação sistemática, pois muitas vezes era o modo de garantir a atenção e o envolvimento do estudante naquela ação. 
Mediada como? Essa mediação se constitui da presença de um docente acompanhando, de perto, a execuçáo de uma atividade de avaliação (entendam prova, pois é o instrumento privilegiado usado pelas escolas). Nessa mediação podem ocorrer várias açóes, dependendo da necessidade do estudante, da área de conhecimento, do tipo de instrumento.

Listaremos alguns exemplos: leitura de enunciado, leitura compartilhada de textos, oferta de material para consulta - um dicionário, por exemplo, ou de um objeto pedagógico como apoio (pode ser uma calculadora); pode ocorrer a necessidade de ação como escriba do estudante; o interlocutor para gravar em áudio uma resposta elaborada oralmente.

Essa estratégia foi constituída na ação docente, junto com os estudantes com deficiência intelectual ou autismo em colaboração com os professores de referência da turma comum. Junto com o estudante significa estar com ele para compreender seus raciocínios e percursos mentais, para agir de modo ajustado, em razão de suas demandas. A interlocuçáo e a diálogo são o mote para provocar o pensamento e o desenvolvimento, na medida em que se estabelece uma relação para compreender como o estudante se envolve com o conhecimento, o que ele sabe e o que precisamos ensinar, como demonstra melhor e do que necessita para avançar.

É importante que essa avaliação mediada seja acompanhada de algum tipo de registro, de modo a favorecer a compreensão de todos - professores, familiares, equipe pedagógica e o próprio estudante, quando for pertinente. $\mathrm{O}$ registro pode ser num formato de relatório, de anotaçôes, de fichas de acompanhamento, realizadas em colaboração.

Para ilustrar, segue o trecho de um relatório de 2017, com alguns registros sobre o momento da avaliação formal realizada por um estudante com deficiência intelectual, do $8^{\circ}$ ano do ensino fundamental de uma das escolas onde trabalhamos:

Sobre a prova de Geografia:

- a prova foi a mesma da turma;

- a professora do AEE foi ledora, com demandas mais intensivas neste momento;

- aqui também se fizeram presentes as observações sobre as instruçôes iniciais da prova, como nas provas anteriores;

- entregamos a prova sem os grampos, com as folhas soltas para que pudesse ir e vir com mais visibilidade sobre o que fez ou precisava fazer, busca de informaçóes em textos;

- o instrumento apresentou-se como muito extenso para o estudante, com demanda de análise de vocabulário usado nas questóes (ex.: Q2. Uso do termo "abarca"), textos longos para análise relativa a questóes diversas;

- foi necessária a explicação sobre os enunciados, objetivando a linguagem. Foi feito uso de marcador de texto para frisar ideias de referência para pensar a resposta; 
- observar que o estudante tende a apresentar uma estrutura de pensamento muito peculiar, procura respostas em informaçóes diretas, no texto, com poucas inferências ou análises mais amplas.

Ou seja, textos/imagens/gravuras que tratam de algum tema, fato, aspecto de forma indireta ou com muitas informaçóes pouco favorecem a localização ou análise das informaçôes por ele. E, também, como em outras áreas do conhecimento curricular, além de ser importante a adequação do instrumento da avaliação/prova, a mediaçáo junto com o professor que trabalha em sua turma com a disciplina seria muito mais produtivo para a estruturação dos caminhos para as respostas a serem elaboradas pelo estudante.

- a formatação/apresentação do instrumento tem relevância para a organização e estruturação do pensamento do estudante. Por exemplo, enunciado da questão numa página e itens da resposta e outra dificulta a organização da informação por ele.

Os ajustes nos instrumentos de avaliaçáo configuraram-se como outra estratégia relacionada à avaliação formal, que foi sendo elaborada na medida em que buscamos garantir maior autonomia aos estudantes. Sáo exemplos de modificaçóes realizadas: uso de enunciados mais diretos, com frases em partes; introdução de glossários com conceitos principais para poder lembrar e relacionar; inserção de imagens para servir de apoio à compreensão; elaboração de banco de palavras para selecionar uma resposta entre outras; desdobramento de uma questão longa em partes. E qualquer ajuste para garantir o acesso e a compreensão.

Além disso, a flexibilização do tempo tem sido uma estratégia bem aplicada, estendendo um pouco mais no mesmo dia ou desdobrando em vários dias a execução da avaliação formal.

A forma de corrigir e dar notas tem sido outro elemento de adequação, a maioria dos professores distribui a pontuaçáo de modo diferente, no entendimento que precisam considerar o estudante em relação a ele mesmo, analisando seu próprio desenvolvimento, a turma não é um parâmetro de comparação que favoreça essa análise sobre o desempenho do estudante com deficiência intelectual ou autismo. Essa prática tornou-se uma estratégia para "driblar" o sistema de notas, que é rígido e exige um lançamento em sistemas computacionais formatados.

Uma pesquisa realizada numa das escolas de nossa atuação (MARIN, 2015), envolvendo práticas de inclusão no segundo segmento do ensino fundamental, ilustra alguns desses aspectos relacionados à avaliação, são excertos retirados de entrevistas realizadas com docentes:

Não tem essa história de reduzir a dificuldade, não há necessidade de fazer tanta adaptaçáo pra aula, talvez para alguma avaliação, a gente vai cobrar de uma forma diferente, mas para aprender, para lidar com o conteúdo, náo. (Professora de Ciências - entrevista) (MARIN, 2015, p.100).

Com relação às notas os alunos também não estão muito acostumados, as meninas reivindicaram quando a Minerva recebeu a nota máxima, mas foi justo, ela cumpriu todos os critérios. Talvez 
os amigos não entendam ainda quando o Jasão, que tem uma prova diferenciada, vai ter uma nota diferente, então de repente um aluno fez uma prova bem, mas ficou com uma nota mais baixa que o Jasão. Mas aí, na minha opinião, para que haja inclusão tem que existir critérios diferentes, entâo aquela nota está baseada na prova que ele fez, foi uma outra prova, com outros critérios, os alunos precisam também entender isso... pro olhar do leigo parece uma injustiça: "como o Jasão pode tirar oito, sei lá..., e eu tirei 7?"

Acho que a gente tem que conversar sobre isso em sala de aula... (Professora de Língua Portuguesa - entrevista) (MARIN, 2015, p.115).

Se eu fosse aluno, isso ia me incomodar, ele ficou com 6,1 de média, se eu tivesse ficado com 5,0 eu ia ficar incomodada. Aí as pessoas falam que não é uma competição, não é uma competição, mas ele está sendo avaliado e eu também, e numericamente ele é melhor que eu. (Professora de Inglês - entrevista) (MARIN, 2015, p.115).

Vejamos que nada é linear e sem conflitos e desafios, teríamos mais a demonstrar, a ilustrar, porém o espaço tem limites. Quisemos aqui propor um diálogo reflexivo.

\section{Propondo o diálogo}

Nossa vivência e estudos indicam que práticas de avaliação precisam ser construídas no cotidiano e na interlocução, mesmo em contextos que permanecem rígidos e aparentemente sem possibilitar maior flexibilidade. Nas escolas onde atuamos, no dia a dia, pudemos participar de açôes diferentes do que é habitual e colaborar com a constituição de outras formas de avaliar, que até estão previstas e bem discursadas teoricamente, que não são novidade, mas geralmente estão no âmbito do discurso e da previsão.

Equidade é isso: fazer diferente para garantir a igualdade. Desde modo, tentamos partilhar algumas ideias, simples e possíveis, para serem pensadas e analisadas a fim de promover a constituição de uma nova cultura escolar que lide com as diferenças, sem excluí-las ou ignorá-las.

Em síntese, apontaremos algumas consideraçóes gerais: a presença de um profissional de referência para apoiar docentes e estudantes em processos de inclusão escolar ainda se faz necessária; avaliaçáo da aprendizagem tem a função de mapear o que o estudante sabe, como ele aprende melhor e que estratégias de ensino podem ser planejadas para impulsionar o desenvolvimento de cada um; a avaliação precisa de registros para além das quantificaçôes; avaliação é processo permeado por interlocução; a avaliação mediada é uma abordagem que pode se estender a qualquer estudante e que muito favorece as pessoas com deficiência intelectual e autismo, e se desdobra em várias estratégias de diferenciação pedagógica. 
Por fim, enfatizamos que a linguagem tem papel fundamental nessas práticas:

Vigotski (1993) argumenta sobre a condição de desenvolvimentohumano a partir da mediaçáo semiótica, pelo signo e pela palavra, pelo outro social. Essa relação, em que o outro é fundamental para significar o mundo histórico-cultural, é possível e viabilizada pela linguagem - instrumento e, ao mesmo tempo, matéria - especificamente humana (SOUZA; DAINEZ; MAGIOLINO, 2015, p. 20).

Este artigo teve a intenção de promover um diálogo sobre avaliação da aprendizagem em tempos de inclusão escolar, onde o trabalho com a diversidade e as diferenças se faz cada vez mais necessário, com Carlos Drummond Andrade compreendemos que "todo ser humano é um estranho ímpar".

\section{Referências}

BRASIL. Avaliaçáo para identificação das necessidades educacionais especiais /Coordenação geral: SEESP/ MEC. Elaboraçẫo: Rosita Edler Carvalho. Brasília: Ministério da Educação, Secretaria de Educação Especial, 2005.

BRASIL. MEC. Política Nacional da Educação Especial na Perspectiva da Educação Inclusiva. MEC, Brasília, 2008. Disponível em: <http://portal.mec.gov.br/arquivos/pdf/ politicaeducespecial.pdf> Acesso em: 05 de maio de 2018.

CAPELLINI, Vera Lúcia M. F.; MENDES, Enicéia G. Alunos com necessidades educacionais especiais em classes comuns: avaliação do rendimento acadêmico. Anais 25a Reuniáo Anual ANPED, 2002. Disponível em: http://www.anped.org.brreunioes25veraluciacapellinit15.rtf Acesso em: 31 maio 2018.

CARDOSO, Ana Paula Lima Barbosa; MAGALHÃES, Rita de Cássia Barbosa Paiva. Educaçáo Especial e avaliaçóes em larga escala no município de Sobral (CE). Revista Educaçáo Especial, Santa Maria, p. 449-464, nov. 2012. ISSN 1984-686X. Disponível em: <https://periodicos.ufsm.br/educacaoespecial/article/ view/6535>. Acesso em: 31 maio 2018. doi:http://dx.doi.org/10.5902/1984686X6535.

CARMINATTI, Simone S. H.; BORGES, Marta K. Perspectivas da avaliação da aprendizagem na contemporaneidade. Est. Aval. Educ., Sáo Paulo, v. 23, n. 52, p. 160-178, maio/ago. 2012. Disponível em: http://www. fcc.org.br/pesquisa/publicacoes/eae/arquivos/1734/1734.pdf

CARNEIRO, Maria Sylvia Cardoso. Reflexóes sobre a avaliação da aprendizagem de alunos da modalidade Educação Especial na Educação Básica. Revista Educaçáo Especial, Santa Maria, p. 513-530, nov. 2012. ISSN 1984-686X. Disponível em: <https://periodicos.ufsm.br/educacaoespecial/article/view/7190>. Acesso em: 31 maio 2018. doi:http://dx.doi.org/10.5902/1984686X7190.

CHRISTOFARI, Ana Carolina; BAPTISTA, Claudio Roberto. Avaliaçáo da aprendizagem: práticas e alternativas para a inclusão escolar. Revista Educaçáo Especial, Santa Maria, p. 383-398, nov. 2012. ISSN 1984686X. Disponível em: <https://periodicos.ufsm.br/educacaoespecial/article/view/6533. Acesso em: 28 maio 2018. doi:http://dx.doi.org/10.5902/1984686X6533.

CORREIA, Luís de Miranda; TONINI, Andréa. Avaliar para intervir: um modelo educacional para alunos com necessidades especiais. Revista Educaçáo Especial, Santa Maria, p. 367-382, nov. 2012. ISSN 1984-686X. Disponível em: <https://periodicos.ufsm.br/educacaoespecial/article/view/6534>. Acesso em: 31 maio 2018. doi:http://dx.doi.org/10.5902/1984686X6534.

CURY, Carlos Roberto Jamil. Direito à educação: direito à igualdade, direito à diferença. Cad. Pesqui., São Paulo, n. 116, p. 245-262, julho 2002. Disponível em:<http://www.scielo.br/scielo.php?script=sci_arttext\&pi$\mathrm{d}=\mathrm{S} 0100$ 15742002000200010\&lng=en\&nrm=iso. Acesso em: 28 maio 2018. http://dx.doi.org/10.1590/ S0100-15742002000200010.

ESTEBAN, Maria Teresa. A avaliação no processo ensino/aprendizagem: os desafios postos pelas múltiplas faces do cotidiano. Rev. Bras. Educ., Rio de Janeiro, n. 19, p. 129-137, abr. 2002. Disponível em <http://www. scielo.br/scielo.php?script=sci_arttext\&pid=S141324782002000100011\&lng=pt\&nrm=iso $>$. Acesso em: 28 maio 2018. 
HOFFMANN, Jussara. Avaliação: mito e desafio: uma perspectiva construtivista. Porto Alegre: Mediação, 2002.http://dx.doi.org/10.1590/S1413-24782002000100011.

JESUS, Denise Meyrelles de; AGUIAR, Ana Marta Bianchi de. O calcanhar de aquiles: do mito grego ao desafio cotidiano da avaliação inicial nas salas de recursos multifuncionais. Revista Educaçáo Especial, Santa Maria, p. 399-416, nov. 2012. ISSN 1984-686X. Disponível em: <https://periodicos.ufsm.br/educacaoespecial/article/view/6532>. Acesso em: 31 maio 2018. doi:http://dx.doi.org/10.5902/1984686X6532

OLIVEIRA, Anna Augusta S. de. Conhecimento escolar e deficiência intelectual: dados da realidade. Curitiba: CVR, 2018.

OLIVEIRA, Anna Augusta S. de.; CAMPOS, Thaís Emília. Avaliação em educação especial: o ponto de vista do professor de alunos com deficiência. Estudos em Avaliaçáo Educacional, v. 16, n. 52 31, jan./jun. 2005. Disponível em: www.fcc.org.br/pesquisa/publicacoes/eae/arquivos/1222/1222.pdf Acesso em: 31 maio 2018.

OLIVEIRA, Anna Augusta S. de.; VALENTIM; Fernanda O. D.; SILVA, Luis Henrique. Avaliaçáo pedagógica: foco na deficiência intelectual numa perspectiva inclusiva. São Paulo: Cultura Acadêmica; Marília: Oficina Universitária, 2013

PACHECO, José; PACHECO, Maria de Fátima. A avaliaçáo da aprendizagem na Escola da Ponte. Rio de Janeiro: Wak Editora, 2012.

PITANGA DE OLIVEIRA, Mariana Corrêa; PLETSCH, Márcia Denise; OLIVEIRA, Anna Augusta Sampaio de. Contribuiçốes da avaliaçáo mediada para a escolarizaçáo de alunos com deficiência intelectual. Revista Teias, [S.1.], v. 17, n. 46, p. 72-89, set. 2016. ISSN 1982-0305. Disponível em: <http://www.e-publicacoes.uerj.br/ index.php/revistateias/article/view/25499/18548>. Acesso em: 31 maio 2018. doi:https://doi.org/10.12957/ teias.2016.25499

PRESTES, Zoia. Quando náo é quase a mesma coisa: traduçóes de Lev Semionovitch Vigotski no Brasil. Campinas, SP: Autores Associados, 2012.

SÃO PAULO. Secretaria Municipal de Educação. Diretoria de Orientação Técnica. Referencial sobre Avaliação da Aprendizagem na área da Deficiência Intelectual do Ciclo II do Ensino Fundamental e da Educação de Jovens e Adultos / Secretaria Municipal de Educação - São Paulo: SME / DOT, 2012.

SILVA, Mariana Cesar Verçosa; MALETTI, Silvia Márcia Ferreira. Avaliação em larga escala de alunos com necessidades educacionais especiais no município de Londrina (PR). Revista Educação Especial, Santa Maria, p. 417-434, nov. 2012. ISSN 1984-686X. Disponível em: <https://periodicos.ufsm.br/educacaoespecial/article/ view/6531>. Acesso em: 31 maio 2018. doi:http://dx.doi.org/10.5902/1984686X6531.

SOUZA, Flavia Faissal de; DAINEZ, Débora; MAGIOLINO, Lavínia L. S. Educação e desenvolvimento humano: modos de mediação e participação nos meandros das práticas educacionais inclusivas. In: PLETSCH, Márcia Denise; MENDES, Geovana Mendonça Lunardi; HOSTINS, Regina Célia Linhares. A escolarização de alunos com deficiência intelectual: políticas, práticas e processos cognitivos. São Carlos: Marquezine $\&$ Manzini: ABPEE, p.15-30, 2015.

SPOSITO, Marilia Pontes. A ilusáo fecunda: a luta por educaçáo nos movimentos populares. São Paulo: Hucitec/Edusp, 1993.

VIEIRA, Soraia da S. P.; MONTEIRO, Maria Inês B. A autonomia do sujeito com deficiência intelectual: possibilidades e impossibilidades vivenciadas no cotidiano da escola. In.: MONTEIRO, Maria Inês B.; FREITAS, Ana Paula de; CAMARGO, Evani A. A.; (Orgs). Relaçôes de ensino na perspectiva inclusiva: alunos e professores no contexto escolar. Araraquara, SP: Juqueira\&Marin, p. 83-109, 2014.

VIGOSTSKI, Lev S. Problemas del desarrollo de la psique - Obras Escogidas - Tomo III. Madri: Visor, 2000.

VIGOSTSKI, Lev S. Pensamento e Linguagem. São Paulo: Martins Fontes, 2008.

\section{Correspondência}

Márcia Marin - Colégio Pedro II. Av. Mal. Floriano, 60-78 - Centro, CEP: 20050-000, Rio de Janeiro, Rio de Janeiro, Brasil.

E-mail: marinvianna2014@gmail.com - braunpatricia09@gmail.com 
Avaliação da aprendizagem em contextos de inclusão escolar

Recebido em 25 de julho de 2018

Aprovado em 8 de agosto de 2018

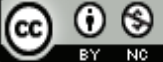

This work is licensed under a Creative Commons Attribution-NonCommercial 4.0 International (CC BY-NC 4.0)

Revista Educação Especial | v. 31 | n. 63 | p. 1009-1024 | out/dez. 2018

Santa Maria

Disponível em: <https://periodicos.ufsm.br/educacaoespecial> 
